\title{
The Solid Phase Bonding of Gold to Metals
}

\section{HISTORICAL AND MORE FUNDAMENTAL ASPECTS}

\author{
R. F. Tylecote \\ Department of Metallurgy, University of Newcastle upon Tyne, England
}

\begin{abstract}
The relative ease with which gold can be welded to itself and to other metals at temperatures below its melting point has resulted in many applications of the solid phase bonding of this metal. In his discussion of the more fundamental aspects of such bonding, the author draws on information relating not only to its use by craftsmen in ancient times, but also to its more recent applications in industry.
\end{abstract}

The term solid phase bonding is used to describe those processes of welding at temperatures below the meiting point of a pure metal and below the solidus of an alloy. Joints may be autogenous, that is, between two pieces of the same metal or alloy or between different metals or non-metals. Welds may be made in very short times such as fractions of a second or over long periods such as days.

In all cases it is necessary to invoke the interatomic forces within the metals which are responsible for their cohesion. Since these forces are effective only within a range of the order of $10 \AA$, the metal surfaces must be as free as possible from adsorbed or other impurities. On a scale of $10 \AA$ most metallic surfaces are exceedingly rough and at room temperature, for example, two pieces of rolled gold touch only at a few points and over a small area under their own weight. Some degree of deformation to ensure close contact is therefore normally necessary for solid phase bonding. By raising the temperature, the plasticity and therefore the ability of the metals to deform may be increased. Alternatively, or in addition, high external pressures may be applied to promote deformation of the surface and improve contact between them. Diffusion (volume and/or surface diffusion) may, however, play a significant role depending upon the temperature at which the process is carried out. Whatever the method used, time also is an important factor, and the various solid phase bonding processes are defined essentially in terms of three parameters: temperature, contact pressure and time (1).

The terms used to describe these processes may either be such (diffusion bonding, pressure bonding) as to indicate the factor of greatest importance in establishing the bond, or alternatively be such (friction bonding, ultrasonic bonding) as to indicate the techniques used to establish the conditions necessary for bonding.
Diffusion bonding is a high temperature, low contact pressure, long time process in which surface diffusion is available for causing movement of metal into the necks of contacting asperities and for bringing about an increase in their area. If the pressure or temperature is high enough, voids between the asperities may be entirely eliminated. Volume diffusion will certainly take place as well but this will not, in a pure metal contact, result in much improvement of the bond.

Pressure welding is mainly the application of high contact pressures for short times, so that surface diffusion plays a small role.

Friction welding is the use of frictional forces and the resulting heat to deform the asperities. Usually it is completed by stopping the relative movement and applying a normal force.

Ultrasonic welding is the use of forces brought about by the acceleration of material due to rapid changes of contact pressure at frequencies of the order of $20 \mathrm{kHz}$ and upwards. These are applied normal or parallel to the surfaces to be joined. On the whole it is probable that the tangential or parallel forces are most effective. As in friction welding, such forces produce heat which helps the deformation process.

Explosive welding is a high energy rate welding process in which one plate is propelled against another by the action of an explosive, but at a carefully arranged angle of incidence (2). It is clearly essential that the impacted plate be malleable. At the high collision velocities and pressures used $(1000 \mathrm{~m} / \mathrm{s}$ and $3400 \mathrm{MPa}$ ) most metals behave as fluids (3). The principles involved are therefore those of a jet striking a plate at an oblique angle and the effects are similar to those of water jets on grease or of bullets on lead sheet. Under certain conditions rippling effects can be obtained which can be used to extend the surface area of the welded joint. From the metallurgical point 

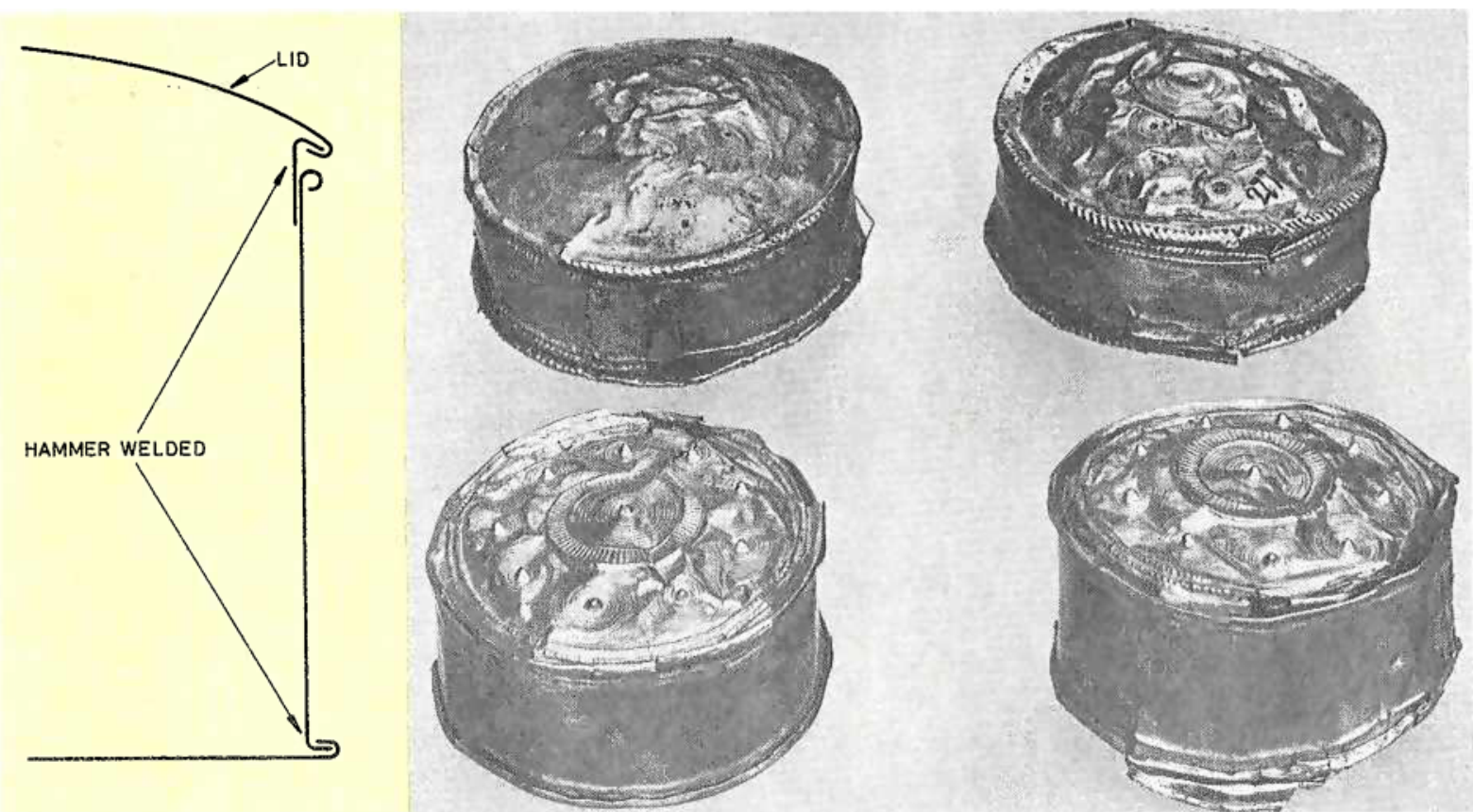

These four gold sheet boxes of the Late Bronze Age were assembled by pressure welding the lapped joints with a small hammer as illustrated in the diagram

The boxes are in the posession of the National Museum of Ireland, by whose kind permission this phorograph of them is reproduced here

of view, the melting point of the metal is rarely reached and diffusion is minimal so that intermetallic compounds are avoided.

\section{The History of Solid Phase Bonding}

Gold is the most easily welded of metals and studies of early artifacts reveal that pressure welding was one of the techniques used in their fabrication. For example, a gold torc from County Roscommon in Ireland, and a group of four sheet metal boxes in the National Museum of Ireland have been assembled by pressure welding (4). The gold boxes date from the Late Bronze Age (1000 to 500 B.C.) and the joints have been made with a small hammer or punch. They are not all now in good condition.

Obviously the applicability of pressure welding in early times was restricted by joint geometry, as it is today. Brazing had to be used when pressure welding was not possible as fusion welding was then quite out of the question. It is not surprising therefore that the only other early application of pressure welding was the use of gold for inlay. A bronze spearhead from Lough Gur, for example, has an inlay of gold wire hammered into incised lines (5).

As regards the techniques used, the preparation of metal surfaces by roughening with a vibrating tool on a rotating wheel has been vividly described by Theophilus (6) and there is no doubt that the need to produce clean and matt surfaces for pressure welding a wide range of metals was well understood long before the 11 th century A.D.
This aspect is also emphasised in the next reference to the pressure welding of gold, namely the comprehensive work by Spring (7) in Germany in 1878. This involved the welding of $5 \mathrm{~cm}$ diameter cylinders, the flat faces of which were turned with degreased tools and clamped together immediately afterwards. Some adhesion occurred at room temperature but if the clamped assembly was heated to $400^{\circ} \mathrm{C}$ for 4 hours it was found impossible to break the weld by hand. Oddly enough Spring did not report that gold could be welded particularly easily. His conditions were apparently so favourable to the satisfactory welding of a wide range of metals that gold was not perceived as outstanding in its behaviour.

In 1888, Christy (8) reported that when two gold buttons (probably obtained by the cupellation of goldlead) were brought together at a temperature well below red heat, they welded so firmly that it took a considerable force to separate them. No doubt it was this observation that led Roberts-Austen to use gold in his experiments in which the role of diffusion in solid phase bonding was first highlighted. He pressed silver cylinders onto similar cylinders of silver $/ 20$ per cent gold alloy and found that after 10 days at about $800^{\circ} \mathrm{C}$ there was considerable diffusion of gold into the silver (9). Later, pure gold was clamped to lead cylinders and after 4 years at $18^{\circ} \mathrm{C}$, it was found that they had welded. The gold had diffused up to at least $2.3 \mathrm{~mm}$ into the lead producing a concentration equivalent to 0.0039 per cent (10). Although this 
phenomenon may be regarded as normal and understandable today, it was one of special interest in 1900. Nevertheless, as late as 1930 volume diffusion was thought (11) to be unlikely, to say the least, and the diffusion that Roberts-Austen had demonstrated was regarded as taking place along grain boundaries.

\section{The Mechanism of Metal-to-Metal Pressure Welding}

A theory of solid phase pressure welding has gradually evolved from increasing knowledge of plasticity and diffusion in metals. In one respect, the absence of an oxide film, gold appears to differ from all other metals. These, including platinum, develop oxide films when exposed to normal atmospheric conditions. Such films attain thicknesses of the order of $50 \AA$ within minutes in dry air. They constitute an obstacle to solid phase pressure welding and have to be broken down by deformation of the soft surrounding metal, so that fresh metal-to-metal contact can be brought about through the wide cracks in the relatively brittle oxide. Although treatment of gold in order to break or remove oxide films is not necessary, other forms of surface contamination occur which render surface preparation favourable to welding.

\section{The Role of Surface Contamination}

According to Finch et al. (12) the improvement in the weldability of gold surfaces which results from prior heating or from scratch brushing is generally attributed to the removal of adsorbed or other surface contaminants in these operations. When gold is heated at $320^{\circ} \mathrm{C}$ for 20 minutes in air, oxygen or nitrogen take up body-centered interstitial positions in its surface layers. These interstitials can be removed by heating in a high vacuum. Interference films have also been observed, even on fire-polished gold, but do not seem to hinder diffusional processes (13).

In dental practice (14) one of the techniques has been to desorb surface films by heating over a spirit flame before using gold foil for fillings. The foil is supported on mica, heated, and then packed with a probe into the prepared cavity where welding occurs under estimated pressures of $80 \mathrm{MPa}$.

Experiments made by the author (15) to evaluate the effect of thermal and mechanical pre-treatment of gold before welding have shown that when a 30 per cent reduction in thickness is imposed during welding, a temperature of $900^{\circ} \mathrm{C}$ applied for 1 minute is required to initiate bonding. Higher temperatures are more effective and longer times are necessary at temperatures below $900^{\circ} \mathrm{C}$. It is quite clear from these experiments that something strongly adsorbed or bound is being removed at the high temperatures. Welds can be carried out with heavier deformation on untreated cold rolled sheet but the time spent on a suitable thermal or mechanical pretreatment is well worthwhile.

Fine scratch brushing is still one of the most readily applied techniques of surface decontamination and works well with most metals. With this process, friction produces a surface temperature rise which can be quite high. The mechanical cutting action of the wires also roughens the surface and completely removes the debris.

If cold welding after high temperature cleaning must be performed without deformation, then, operation in vacuum has advantages. Nishikawa et al. (16) have observed the welding of gold to platinum and iridium, in the conditions of a field ion microscope, with hard metal tip to soft plate configurations. In most cases material transfer was observed from plate to tip immediately after contact, the interfacial layer being 10 to 50 atomic layers thick ( 20 to $150 \AA$ ). The new material had the same crystal orientation as the old showing that recrystallisation was occurring at very low temperatures or else that diffusion was taking place under epitaxial conditions. If surface diffusion was the main mechanism this is not really unexpected.

The use of vacuum to eliminate adsorbed films and reduce the amount of deformation necessary to perform welding has been invoked in a patent (17). Vacuum of the order of $10 \mathrm{~Pa}$ was found to decrease the applied pressure required to weld gold plated surfaces from the range 70 to $140 \mathrm{MPa}$ to the range 6 to $11 \mathrm{MPa}$. Cuthrell and Tipping (18) have applied laser interference microscopy to determine the results of welding gold wires in vacuum after cleaning by sputtering techniques. While such techniques are clearly useful, the application of vacuum processes for cleaning and welding is by no means easy.

Surface contamination of gold is not restricted to atmospheric films. In the production of microelectronic components, residual organic films from the photoresist material used in printed circuit manufacture may also be present. The welding of gold wires to a gold metallised surface contaminated with such organic films is a two-stage process (19). The first stage involves the breakdown of the contaminants and is strongly dependent on temperature and the characteristics of the films. The second stage involves the growth of the contact areas by surface diffusion. Jellison found that, in the absence of pressure, the activation energy for this process is of the order of 46 $\mathrm{kJ} / \mathrm{mol}$ which is typical of the surface diffusion process (20). The time dependence of contact area growth showed a parabolic relationship. Under high external loads, growth exhibited little temperature dependence, as was expected. The effect of the organic residue in decreasing the growth rate was only one order of magnitude greater than for normal 
atmospheric contamination which suggests that the contamination from the photo-resist behaved like a non-polar lubricant (21).

Once surface films on gold have been dispersed or destroyed, welding is then merely a case of bringing sufficient material in close enough contact so that the interatomic forces that hold the atoms of metals together can take over.

\section{The Role of Mechanical Deformation}

A metal may be said to consist of positive ions distributed at the points of a geometric lattice. These ions consist of a nucleus surrounded by an electron cloud. Between the ions are conduction electrons which are free to move in a relatively unrestricted manner. The material is held together by the attraction between the positive ions and the free electrons. This attraction is at a maximum at a distance of the order of 3 to $4 \AA$ and falls off rapidly as the distance increases to $10 \AA$.

Mechanical deformation is effective in bringing enough material to within the attractive distance of the interatomic forces for bonding to occur. Although breaking on removal of the applied pressure can result from the internal stresses associated with work hardening, the risk of this is minimised by welding at temperatures above the recrystallisation temperature. In the case of pure gold, and in particular dental 'cohesive' gold, however, this temperature is low.

The importance of hardness on the cold welding of gold-copper alloys has recently been highlighted by Bailey and Sikorski (22) who used a welded cold torsion specimen for their work. They found that the weld strength decreased as the alloy strength increased due to solid solution hardening in both the ordered and disordered states.

Ahmed and Svitak (23) have critically examined the work done by others (24) particularly on the type of joint most often met with in microelectronics, namely that established by thermocompression bonding between gold wire and gold metallised ceramic substrates. The predictions of slip line plasticity theory were checked using silver markers placed between the joint surfaces. Not unnaturally they found that the relative sliding motion that seems so important to the break-up of oxide films on base metals was not necessary in the welding of gold with its freedom from surface oxide films. Needless to say there is always some stretching, typically 5 to 17 per cent, of the interfacial regions which is a concomitant of the overall deformation used.

Stapleten (25) used a symmetrical arrangement (see illustration) in which two gold leads were welded to two gold metallised steel substrates to give two types of bond; an A-B bond between a rigid surface and wire and a symmetrical wire-to-wire bond, B-C. In

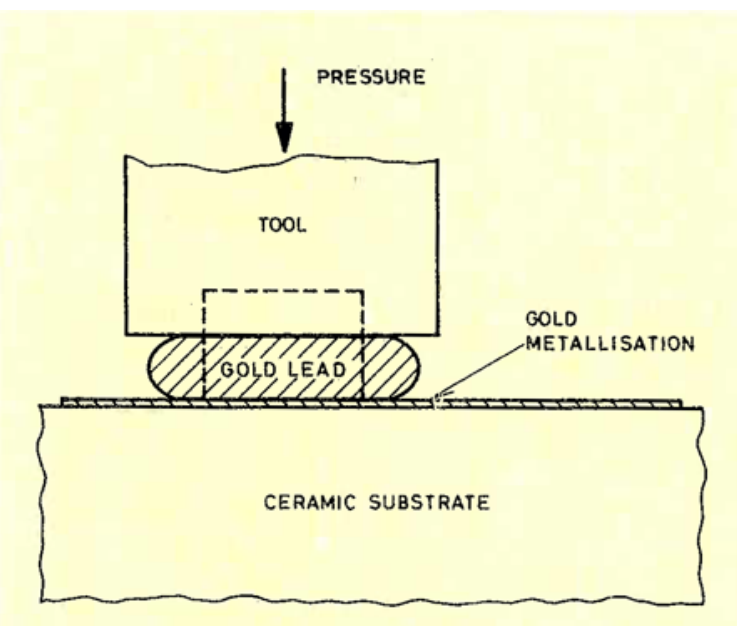

Schematic representation of lead attachment by thermocompression bonding between a gold wire and a gold metallised ceramic substrate. After (23)

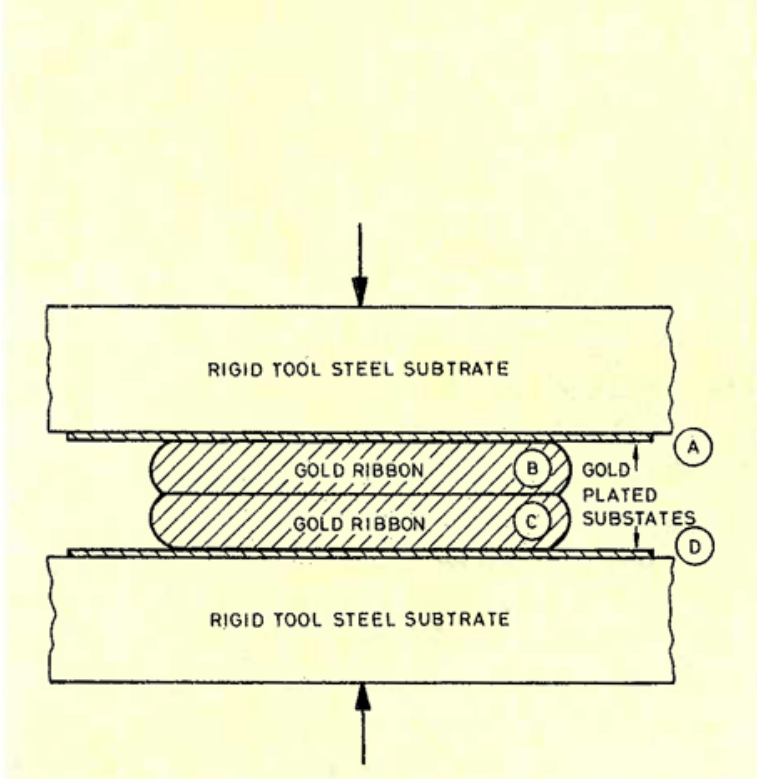

Configuration used by Stapleton (25) to evaluate the relative importance of surface elongation and interfacial shear stress in bonding

this way it was possible to get both types of deformation - one with and the other without relative displacement. He confirmed that with an overall deformation of 12 per cent, a better weld was produced where relative movement was possible (junctions $\mathrm{A}-\mathrm{B}$ and $\mathrm{C}-\mathrm{D}$ ) than where it was not (junction B-C). The general conclusion, which was in agreement with that from work on other metals (26), was that with poor or borderline welding conditions relative movement was a necessity, while with good conditions such as high deformations and/or temperatures, such relative movement was unnecessary. 
In ultrasonic welding the deformation is restricted to a very thin zone at the interface. The overall deformation which is required for bonding is therefore markedly reduced. Furthermore, as in cold pressure welding but not as in thermocompression bonding, no additional heat is necessary. Heat is of course produced by the process itself, and some authorities (27) have suggested that this and the high frequency vibrations can give rise to problems, such as differential contraction stresses and mechanical damage. Pfluger and Sideris (28) found, however, that ultrasonic bonds between gold ribbons, $0.025 \mathrm{~mm}$ thick and $0.075 \mathrm{~mm}$ wide, and gold metallised substrates had strengths of over 75 per cent of that of gold itself.

\section{The Role of Diffusion}

Depending upon the process selected, welding can be performed at ambient or at elevated temperatures. In the latter case all the auxiliary processes that rely on diffusion are aided, while in the former they have a minimal effect.

When cold welding at low deformations for short times 'necks' of welded material are interspersed with voids. As the temperature is increased after contact has been established, various diffusional processes take place. First, surface diffusion, which is not so temperature dependent, allows material to move into and enlarge the 'necks' of the contact areas. Next, the more temperature dependent processes of grainboundary and volume diffusion occur which on the whole have little effect on the bond strength until temperatures approaching the melting point are reached. It must be borne in mind, however, that heat treatment may not necessarily be advantageous, it can cause reduction in strength due to the annealing of the cold-worked metal produced by deformation in welding. Cold working can be very significant, for instance in the case of direct gold restorations in dental work (14) it has been shown to give rise to increases in hardness of from 27 to $65 \mathrm{HB}$.

Hot welding, where the temperature is held above the recrystallisation temperature, will close the spaces between the microscopically uneven surfaces and, provided that the time is long enough and the temperature is high enough, complete elimination of the interface will take place. The temperatures necessary for this are very close to the melting point and the process needs very long times, so much so that it is uneconomic. Pressure is thus a better way of achieving the closing of pores.

Self-diffusion coefficients (see Table I) are relatively low and in most cases considerably lower than those involving the diffusion of one metal in another by interstitial means (29). Thus, diffusion can be markedly accelerated (by as much as three orders of magnitude) when a suitable metal is used as an intermediate between the two pieces of metal to be joined. For instance, a British patent (30) recommends the use of a solid silver-lead interlayer to facilitate the bonding of two gold-plated surfaces of ceramic or metal.

Diffusion in the liquid state is also about three orders of magnitude faster than in the solid state at the same temperature. Extrapolation was used to give the figures shown in Table II. Liquid intermediate layers can therefore be used to accelerate diffusion in the early stages of bonding. In the later stages, diffusion in the parent metal and the formation of a solid solution will cause the elimination of the liquid phase and the system will become a truly solid one. Altogether, the process is somewhat related to brazing.

Amalgamation with mercury has been used for gilding since pre-Roman times. Ornellas and Catalano (31) have investigated the bonding of gold to gold (99.93 per cent) with the aid of interlayers of mercury, indium (melting point: $156^{\circ} \mathrm{C}$ ) and gallium (melting point: $40^{\circ} \mathrm{C}$ ) from room temperature to $100^{\circ} \mathrm{C}$. Naturally the effect of mercury was good at $100^{\circ} \mathrm{C}$, and the weld improved as the contact time was increased from 2 to 78 days, after which the mercury was found to have penetrated $25 \mu \mathrm{m}$ into the gold. The welds with indium were true solid phase welds and were not as good as those made with mercury, probably because of the tenacious film of $\operatorname{In}_{2} \mathrm{O}_{3}$ In all cases the welds made with gallium were poor. This was probably due to the production of brittle intermetallic compounds rather than oxide films.

The idea of using mercury as an intermediate is invoked in a U.S. patent (32). As this requires a temperature of $100^{\circ} \mathrm{C}$ and a time exceeding two days, any application must be directed to special fabrications rather than the rapid assembly of gold components.

Recent work has shown how the surface selfdiffusion of gold can be markedly accelerated by bismuth (33). The effect of bismuth on gold is to increase the coefficient of surface diffusion in the temperature range 600 to $950^{\circ} \mathrm{C}$ by a factor of $10^{4}$. The gold ( 99.999 per cent) was exposed for 1 to 10 hours to a slow stream of bismuth-containing oxygen, which passed over its surface. Either a low melting point gold-bismuth intermetallic compound, one atomic layer thick is formed (34) or else some gold atoms can climb onto and move across the adsorbed layer.

It has been known for a long time that diffusion processes can be accelerated by the temporary production at the interface of fluorides and other low melting point compounds giving enhanced mobility which are later dissociated by a change of temperature or pressure (35). 
Although it is to be expected that any process facilitating diffusion will be beneficial to bonding and will improve the integrity of a joint, this is not always the case. When joining dissimilar materials, diffusion can lead to the production of phases such as intermetallic compounds that are often brittle. An example of this involving gold is 'purple plague' which can occur on gold-toaluminium junctions when time and temperature are such as to induce sufficient diffusion. The mechanical deterioration of goldaluminium joints is associated (36) with the development of Kirkendall voids as a result of the higher diffusion rates of aluminium as compared with those of gold, and a purple colouration is not always indicative of deterioration (37).

The diffusion that takes place when using lead-tin solders to join gold is one reason for the use of pressure welding processes as alternatives. Poor joints may occur during the lead-tin soldering of gold or gold plated parts due to the formation of a layer containing large dendritic crystals of brittle $\mathrm{AuSn}_{4}$ $(38,39)$ when the gold dissolves in the solder and its concentration rises above about 5 per cent. This possibility increases with the thickness of the gold coating. Naturally the amount of gold dissolved is very temperature sensitive. Solubility is reduced by the use of low melting lead-tin-indium solders but these give weaker joints. The gold leaching or 'scavenging' characteristics of lead-tin solders have been discussed by Novick and Kroehs (40).

To reduce the amount of gold used in wires, and yet retain the favourable properties of gold, base metals plated with gold can be used. But naturally during high temperature operations, such as hot welding, diffusion problems may occur. Tests carried out in vacuum to find metals which will inhibit diffusion in gold-plated copper at 400 to $500^{\circ} \mathrm{C}$ showed that only nickel and chromium were effective in this role (41). The other metals tried were platinum, palladium and rhodium which were thought to fail due to their atomic radius being greater than that of copper, thus permitting interstitial diffusion of copper through them. Nickelmagnitude
Table :

Constants. After Barrer (32)

\begin{tabular}{|c|c|c}
\hline $\begin{array}{c}\mathrm{D}_{0} \\
\mathrm{~cm}^{2} / \mathrm{s}\end{array}$ & $\begin{array}{c}\mathrm{Q} \\
\mathrm{cal} / \mathrm{g} . \text { atom }\end{array}$ & $\begin{array}{c}\mathrm{D} \\
\text { at } 300^{\circ} \mathrm{C} .\end{array}$ \\
\hline 5.1 & 27900 & $1.6 \times 10^{-10}$ \\
$4.9 \times 10^{-1}$ & 13000 & $6.2 \times 10^{-6}$ \\
$7.5 \times 10^{-2}$ & 15200 & $1.2 \times 10^{-7}$ \\
$7.7 \times 10^{-3}$ & 18600 & $7.1 \times 10^{-10}$ \\
& & at $800^{\circ} \mathrm{C}$. \\
$1.1 \times 10^{1}$ & 57200 & $3.2 \times 10^{-11}$ \\
$1.2 \times 10^{-2}$ & 37500 & $4 \times 10^{-10}$ \\
$8 \times 10^{-1}$ & 38000 & $2 \times 10^{-8}$ \\
1.0 & 45000 & $1 \times 10^{-9}$
\end{tabular}

Note: In all the above instances the activation energy of diffusion of one metal in another is less than that for self diffusion. $D_{0}$ generally lies in the range of 1.0 to 0.01 , that is of two orders of

Table II

Liquid and Solid Diffusion Coefficients

\begin{tabular}{|c|c|c}
\multirow{2}{*}{$\begin{array}{c}\text { Temp. } \\
{ }^{\circ} \mathrm{C}\end{array}$} & Solid & Liquid \\
\cline { 2 - 3 } & $8.1 \times 10^{-8}$ & $5.1 \times 10^{-5}$ \\
500 & $2 \times 10^{-8}$ & $6.1 \times 10^{-5}$ \\
670 & - & $8.0 \times 10^{-5}$ \\
660 & &
\end{tabular}

phosphorus electroplates were found to be better barriers than pure nickel. It is possible that cobalt could be used as its atomic radius of $1.26 \AA$ is very close to those of copper $(1.28 \AA)$ and nickel $(1.25 \AA)$.

Two of the most important dissimilar combinations are those between gold, and silicon and germanium respectively, which are important semi-conductors.

The welding of gold to silicon has been investigated by Tabeliev and Rossoshinskii (42) at a temperature of $400^{\circ} \mathrm{C}$, which is below that at which the goldsilicon eutectic forms in the welding times used $(0.5$ to $5 \mathrm{mins}$ ). A $3 \mathrm{~mm}$ diameter molybdenum electrode was used against the gold foil $(0.1 \times 0.45 \mathrm{~mm})$. These authors found that the time $\mathrm{T}$ in minues to give maximum strength welds varied with the applied load in grams (P) according to the relationship:

$$
\mathrm{T}=1000 \mathrm{P}^{-0.65}
$$

Diffusion in the times used was predominantly via the surface and grain boundaries and no molten phase formed. The applied loads varied from 286 to $2100 \mathrm{~g}$, with resulting deformations from 2.2 to 50 per cent. Anderson, Christensen and Andreatch (43) studied the thermocompression bonding of gold. wire to both silicon and germanium. The gold wire was prepared by annealing in a flame or cleaning in acid, and the semiconductor was washed in alcohol, The 
temperatures reached were below those of the relevant eutectics, that is gold was welded to germanium at $250^{\circ} \mathrm{C}$, while the gold-germanium eutectic melts at $356^{\circ} \mathrm{C}$. Contact pressures were as high as $35 \mathrm{MPa}$, which caused the deformation of the wire to be in the range 10 to 30 per cent. Of the combinations examin$\mathrm{ed}$, the bonding of gold to germanium was the easier to perform. In the times used (second to a few minutes) no diffusion was detectable under the microscope and no dislocations were moved or created in the semiconductors.

The standard form of gold-to-silicon eutectic bond and the bonding of gold-plated Kovar (iron-nickelcobalt) to silicon $/ 20$ per cent germanium have been reported upon by Yost (44). The joining materials were gold $/ 2$ per cent silicon and gold $/ 22$ per cent germanium which melt at 370 and $356^{\circ} \mathrm{C}$ respectively. Low joint strengths were associated with semiconductor surfaces showing little dissolution apparently due to surface oxides. This could be obviated with a preliminary etch in 10 per cent HF. In good welds, failure took place within the semiconductor.

\section{Conclusion}

Two special attributes of gold contribute to making it the easiest of metals to bond to other metals by the simple application of pressure and/or heat at temperatures below its melting point. These are firstly its ductility, and secondly the fact that it does not form oxide films on its surface, even when heated in air. As a result gold can be bonded to itself and to other metals in the solid state under a wide range of pressures and temperatures and by a wide range of techniques.

The main objective in each instance is to establish close contact between the metal surfaces over as large an area as possible. In the case of gold, contaminating or adsorbed layers on its surface which could obstruct such close contact are easily removed by heating or by scratch brushing. If only low pressures are to be applied such pretreatment may be critical and times and/or temperatures should be adjusted so that the limited areas of contact which can be achieved initially can grow by diffusion. If high pressures are to be applied such pretreatments may be less critical and the role of diffusion in promoting the growth of the initial contact is normally a minor one unless temperatures are very high. The nature of the stresses at the interface can, however, be significant.

Under most conditions surface diffusion appears more important than lattice or grain boundary diffusion in filling the voids in the contact zone as established under pressure. Liquid or low melting metals such as mercury, gallium, and indium are effective in increasing diffusion rates in the contact area. Where diffusion results in the formation of Kirkendall voids or of intermetallics the strength of the final bond may be adversely affected.

If bonds have to be established between base metals under mild conditions, the coating of their surfaces with gold may be advantageous, since the bond which has finally to be established is gold to gold.

\section{References}

1 R. F. Tylecote, 'The Solid Phase Welding of Metals', Arnold, London, 1968

2 G. Bechtold, I. Michael and R. Prümmer, Gold Bull., 1977, 10, (2), 34-37

3 R. F. Tylecote, ref. 1, 260-272

4 R. F. Tylecote, 'Metallurgy in Archaeology', Arnold, London, 1962

$5 \mathrm{~J}$. Evans, 'Ancient Bronze Implements, Weapons and Ornaments of Great Britain and Ireland', London, 1881, 312-313

6 Theophilus, 'De Diversis Artibus', translated from the Latin with introduction and notes by C. R. Dodwell, Nelson, London, 1961, 99

7 W. Spring, Z. Phys. Chem., 1894, 15, 65-78

8 S. B. Christy, Trans. Am. Inst. Metall. Eng., 1888, 17, $1-45$

9 W. C. Roberts-Austen, Phil. Trans. Roy. Soc, 1896, 187 $383-415$

10 W. C. Roberts-Austen, Proc. Roy. Soc., 1900, 67, 101-105

11 C. F. Elam, F. Inst. Met., 1930, 43, 217

12 G. P. Finch, A.G. Quarrell and H. Wilman, Trans. Farad. Soc., 1935, 31, 1051-1080

13 O. L. Anderson, Wear, 1961, 4, 253

14 E. W. Skinner, "The Science of Dental Materials', W. B. Saunders Co., Philadelphia, 1937, 220

15 R. F. Tylecote, Br. Weld. F., 1954, 1, 117-135

16 O. Nishikawa et al., Surf. Sci., 1971, 26, (2), 677-682

17 R. C. A., U.S. Patent 3,921,885; in Gold Bull.. 1976, 9, (3), 107

18 R. E. Cuthrell and D. W. Tipping, IEEE Trans. Parts. Hybrids Packag., 1974, PHP-10, (1), 4-10

$19 \mathrm{~J}$. L. Jellison, "Kinetics of Thermocompression Bonding to Organic Contaminated Gold Surfaces', Sandia Laboratories Report, Albuquerque, N. M., 1976

20 R. F. Tylecote and E. J. Wynne, Br. Weld. F., 1963, 10, 385-394

21 I. B. Baranov, Avto. Svarka, 1958, 1, 63

22 J. A. Bailey and M. E. Sikorski, Wear, 1969, 14, 181-192

23 N. Ahmed and J. J. Svitak, Solid-Staze Tech., 1975, 18, 25-32

24 L. Dries, M.Sc. Thesis, Dept. of Metall. and Mater. Sci., Lehigh Univ., Bethlehem, Pa., June 1974

25 R. P. Stapleton, M.Sc. Thesis, Dept. of Metall. and Mater. Sci., Lehigh Univ., Bethlehem. Pa., June 1974

26 R. F. Tylecote, ref. 1, 284

27 E. Keonjian, 'Microelectronics: Theory, Design and Fabrication', McGraw-Hill, New York, 1963, 162

28 A. R. Pfluger and X. N. Sideris, SAMPE Q., 1975, 7, (1), 8-19

29 R. M. Barrer, 'Diffusion in and Through Solids', Cambridge Univ. Press, 1951

30 Mullard Ltd., Br. Patent 1426873

31 D. L. Ornellas and E. Catalano, Rev. Sci. Instrum., 1974, 45, 955

32 U.S. Energy Res. and Dev. Adm., U.S. Patent 3,923,231

33 J. P. Biberian and G. E. Rhead, C.R. Acad. Sci. (C), 1975, 280, 489; in Gold Bull., 1976, 9, (3), 80

34 G. E. Rhead, Surf. Sci., 1969, 15, 353

35 M. Eudier, 'Powder Metallurgy Symposium', Iron \& Steel Institute, London, 1954

36 E. Philofsky, Solid-State Electron., 1970, 13, 1391-1399

37 C. W. Horsting, Proc. 10th Annu. Conf. IEEE, New York, $1972,155.158$

38 G. W. A. Dummer, Electron and Power, 1966, (7), 202-206

39 P. Ainsworth, Gold Bull., 1971, 4, (3), 47-50

40 D. T. Novick and A. R. Kroehs, Solid-State Tech., 1974, 17 , (6), $43-47$

41 L. B. Hunt, Gold Bull., 1975, 8, (2), 52

42 U. D. Tabeliev and A. A. Rossoshinskii, Avto. Svarka, 1966 (2), 19-22

43 O. L. Anderson, H. Christensen and P. Andreatch, f. Appl. Phys., 1957, 28, 923

44 F. G. Yost, f. Electron. Mater., 1974, 3, (2), 353-369 